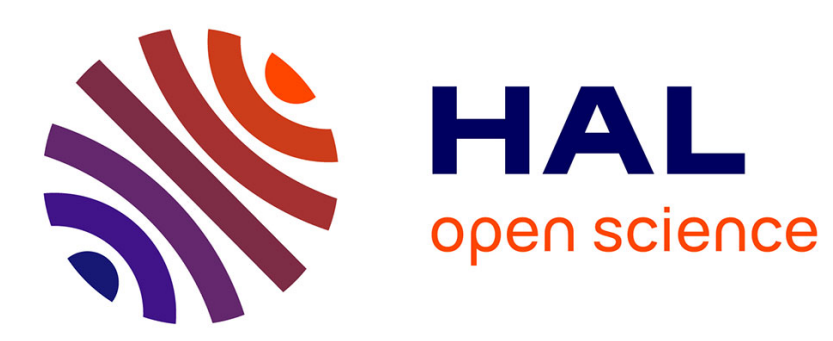

\title{
Characterization of the JAR Sealants in the Fluid Collections of the Muséum National D'histoire Naturelle
}

\author{
Michel Sablier, C. Davron, M. Herbin
}

\section{To cite this version:}

Michel Sablier, C. Davron, M. Herbin. Characterization of the JAR Sealants in the Fluid Collections of the Muséum National D'histoire Naturelle. Collection Forum, 2020, 34 (1), pp.87-100. 10.14351/08314985-34.1.87 . hal-03375917

\section{HAL Id: hal-03375917 \\ https://hal.science/hal-03375917}

Submitted on 23 Nov 2021

HAL is a multi-disciplinary open access archive for the deposit and dissemination of scientific research documents, whether they are published or not. The documents may come from teaching and research institutions in France or abroad, or from public or private research centers.
L'archive ouverte pluridisciplinaire $\mathbf{H A L}$, est destinée au dépôt et à la diffusion de documents scientifiques de niveau recherche, publiés ou non, émanant des établissements d'enseignement et de recherche français ou étrangers, des laboratoires publics ou privés. 


\section{Characterization of the jar sealants in the fluid collections of the Muséum}

\section{National d'Histoire Naturelle}

$$
1,{ }^{*} \quad 2,3
$$

3 M. Sablier , C. Davron , and M. Herbin

4

1

5 Centre de Recherche sur la Conservation, Muséum national d'Histoire naturelle, Paris, France. 2

6 Unité Mécanismes Adaptatifs et Evolution (MECADEV, UMR 7179), Muséum National d'Histoire

$7 \quad$ Naturelle, Sorbonne Universités, CNRS; CP55, 57 rue Cuvier Paris, France.

$8{ }^{3}$ Direction des collections - Muséum national d'Histoire naturelle, 57 rue Cuvier Paris, France.

9

10 * Contacting author: M. Sablier, Tel: +33.1.40.79.53.23, Email: michel.sablier@mnhn.fr 11 
Abstract

Over the centuries, the composition of jar sealants in natural history museum fluid collections has changed but has been little documented. Consequently, it is of paramount interest to increase our knowledge of sealant composition as well as to correlate this information to the date of manufacture and preparation. The proposed approach is based on the development of an analytical protocol to characterize the composition of sealants encountered in fluid collections of the MNHN. A method based on FTIR spectroscopy and Pyrolysis-GC/MS was employed to investigate sealant composition and was demonstrated to be efficient for the identification and characterization of waxes and resin additives in sealing samples. First results are very promising and should be continued on a large scale for an exhaustive analysis of the fluid collections of the Muséum National d'Histoire Naturelle in Paris. 
Until the 17th century, most specimens in natural history collections were preserved dry, consisting mainly of skeletons, taxidermy preparations, dehydrated specimens, and casts. Many of the specimens which were kept in fluids were not well preserved and degraded more or less quickly (but mostly inevitably). At that time, specimens were collected and then preserved without undergoing any prior treatment or fixation; for the most part they were simply immersed in a preservation solution (Herbin 2013). The choice to preserve the appearance of specimens evolved with the development of advanced research on better means of fixation of specimens. The aim was not only to preserve the external appearance of organisms or organs, but also to fix the tissues and their structures so that they could be studied later (Daubenton 1784). Most of this research was intimately linked to advances in methods of teaching anatomy and in the field of histology. The conservation of natural history specimens has always posed a problem for people, including conservators and curators, who are responsible for looking after their perpetuation.

An important concern perpetuated from the early days of fluid collections was how to close a container hermetically to limit the evaporation of the preservative solution (Daubenton 1749) and to limit the influx of oxygen. The study of the history of jar sealing illustrates the clash of the theoretical methods of some with the experimentation of others, and the contribution of practice to adjust established approaches (Pequignot 2019). Jar sealing techniques applied to fluid collections have evolved in close correlation with the evolution of conservation techniques in fluid collections. Daubenton made an inventory of the techniques using metal sheets, white lead, or pig's bladders in the middle of the 18th century (Daubenton 1749) and 
developed a recipe for an amalgam based on mercury and lead. Air tight closure remained a concern for naturalists who, failing to find a suitable means of sealing containers, often found themselves powerless in the face of the evaporation of preservative fluids and the gradual degradation of specimens. In addition, given the growing preponderance of naturalist expeditions around the world, the need to find practical and effective solutions for sealing containers became urgent. Among the most important developments was the introduction of the lithocolle recipe by François Péron and Charles-Alexandre Lesueur (Péron \& Lesueur 1810) which combined cork stoppers, turpentine oil, wax, resin, and red ocher to allow in situ jar sealing with a minimum of materials and best practical efficiency. Later, the introduction of the use of rubber (Maissiat 1847) led to the usage of this material in commercial seals applicable to natural history collections. Since the middle of the 20th century, the use of silicone sealants has increased.

As a consequence, considering both the chronology and the typology of jar sealants is the only reasonable angle allowing a thoughtful and rational approach to the conservation and management of fluid collections.

The quality of sealing systems in fluid collections is a key factor for their stability and long-term performance. The evaporation of preservatives, such as ethanol aerosols or formaldehyde gas, is a major problem in fluid collections that leads to a decrease in final concentration of the preservative in the solution, which is harmful to the specimen (Carter \& Neumann 2016) and to airborne emissions that may accumulate in the storage area or the lab which can be harmful for staff members, researchers, and visitors (Burroughs et al. 2006; Defendini 2016). Another recurrent problem relates to the acidification of the storage medium resulting from the influx of oxygen 
in the jar (e.g., oxidation of formaldehyde to formic acid, of ethanol to acetic acid, of lipids to fatty acids that opacify the fluid, and color fading caused by oxidation of pigments). These different aspects of fluids are largely dependent on the integrity of the closure, which can be compromised e.g. by microfissures in seals due to repeated expansions and contraction of sealants, on hardening of the sealants, and on the resistance of the seal to solvent vapors and oxygen. However, whether historical or current, their chemical nature, durability, and effectiveness remains largely unknown (van Dam 2000; Herbin 2017; Collins 2014).

A project designed to acquire a better knowledge of the composition and behavior of container seals used in the fluid collections of the Muséum National d'Histoire Naturelle (MNHN) was initiated. As sealing practices have evolved historically and this knowledge has often been abandoned or forgotten in favor of new techniques that were considered easier to implement or more efficient at the time. However, understanding these practices is important, not only for the history of the collections, but above all to also understand, from a conservation perspective, the materials that have proved to be the most effective and that could inspire new approaches.

According to some sources (Simmons 2014; Moore 2007; Herbin 2013) the hermetic seal of historic containers may consist of waxes, bitumen, vegetable resins (e.g. pine resin), paraffin, oils (linseed, turpentine) or a mixture of these components (plus pigments for aesthetic appearance). The naturalist François-Auguste Péron describes an effective luting called "lithocolle" as a mixture of "yellow wax", rosin, red ochre, and turpentine oil (Péron in Péron \& Lesueur 1810). Sometimes, to complete the seal, a pig or sheep bladder was added, sometimes covered with a metal sheet made of lead or tin (personal observation). The possible impact on seals permeability 
is unknown at this time. Today, contemporary sealing techniques employ different types of silicone which can be more efficient but are also more difficult to remove to access the specimen and are less flexible when environmental conditions (temperature, humidity) change in storage rooms or in galleries. It is therefore possible to classify the sealing techniques according to their composition by using the appropriate techniques for the analysis of these complex mixtures. Waxes, for example, have been widely studied (in other fields) since the advent of separation methods but their characterization remains an analytical challenge. The difficulty lies in the diversity of their components: alkanes, alkenes, acids, alcohols, long chain esters (unsaturated, saturated, or possibly hydroxylated) and polyesters. In addition, the physico-chemical properties of these components make their separation under conventional analytical conditions complex, particularly for mixtures. Their study therefore requires the use of analytical tools with increased potential for the elucidation of their composition.

\section{Methods}

Gas chromatography (GC) is one of the most widely applied separation techniques for the identification of organic samples, keeping in mind that these samples must be volatilized for analysis. Most studies of organic materials performed by means of gas chromatography $(\mathrm{GC})$ used flame ionisation detectors (FID), which is a quantitative detector but lacks identification potential. In GC-FID, the compounds emerging from the column are recognized by their retention time so that standards and reference samples are required to positively identify the complex mixtures that compose the samples. The availability of appropriate standards is consequently a limiting step in 
122 the application of GC-FID. The higher capacity of mass spectrometry (MS) detectors coupled with the GC for identifying compounds, as well as their greater sensitivity, are the main reasons for the extended use of GC/MS instruments in analytical laboratories.

The analytical study of bulk samples (e.g., natural products, coatings) by means of conventional chromatographic separation techniques (such as gas chromatography, thin-layer chromatography and liquid chromatography) has been notably limited given the high molecular weights of their components. This drawback can be overcome by applying a high temperature heating process, commonly between 500 and $800^{\circ} \mathrm{C}$ (significantly higher than room temperature) to obtain a sort of unspooling of the polymeric structures of the sample, which enables the recovery of information through the identification of building-blocks. This is the so-called analytical pyrolysis which results in the decomposition of the architecture of the bulk sample into smaller and volatile fragments.

The process of analytical pyrolysis is commonly reported as being applied for the first time in the second half of the 19th century to characterize natural rubber as a polyisoprene compound (Greville Williams 1862). Thereafter, progress for its use was slow until the advent of new analytical techniques such as organic mass spectrometry (MS) and the development of modern gas chromatography (GC) in about the middle of the 20th century. Firstly, linked directly with MS, pyrolysis was latterly coupled to a gas chromatograph conducting the separation of the pyrolytic products and their identification by means of their retention time. The first main applications were in forensic science. In fact, the complexity of the thermal degradation processes implicit in pyrolysis induces a noticeable difficulty in 
accomplishing a satisfactory identification of materials from the recovered building blocks without the use of reference materials. The routine combination of pyrolysisGC and MS (Py-GC/MS) has led to increasing applications of the characterization of synthetic and natural polymers since an MS analyzer allows more accurate identification of the pyrolysis products separated in the column (Sobeih et al. 2008).

As a consequence, Py-GC/MS offers several advantages compared to conventional GC/MS, namely (i) reduced and limited sample preparation, (ii) high sensitivity and limits of detection for sample sizes in or below the $\mu \mathrm{g}$ range, and (iii) the possibility of obtaining structural information from the pattern of fragmentation produced as a consequence of the pyrolysis process, the so-called fingerprint identification. In contrast to conventional GC/MS, the resulting chromatograms often are more complex than those obtained by conventional GC/MS due to the increased number of peaks corresponding to the pyrolytic fragmentation of the original molecular structure, and thus provide reliable identification of the sample through its characteristic "fingerprinting".

Three types of pyrolyzers are commercially available: Curie-point, furnace, and filament pyrolyzers. Curie-point instruments use the ferromagnetic properties of a conductor interacting with a high radio frequency to fix the pyrolysis temperature. A pyrolysis chamber indirectly heated by ceramics is commonly used in the furnace pyrolyzer. In the filament pyrolysis system, the required high temperatures are reached by applying an electric current to a platinum coil.

However, even if pyrolysis simplifies the direct analysis of samples, a chemical derivatization step can improve the performance of the separation in the chromatographic column, particularly if polar structures are present or assumed in 
170 the bulk sample. The most common derivatization technique relies on methylation

171 reactions associated with the pyrolytic process inside the pyrolyzer itself. This

172 technique, called thermally assisted hydrolysis and methylation (THM), is commonly

173 conducted with a liquid derivatization reagent added to the sample before pyrolysis.

174 In brief, since its first application in the 1960s, analytical pyrolysis linked to GC/MS

175 has been successfully applied to the identification of natural oils and waxes as well

176 as to terpenoid resins and binding media, including synthetic organic polymers such

177 as acrylic and alkyd resins.

178 In the course of our work, reference samples of beeswax, paraffin and resin (these

179 latter two samples coming from the reserves of the fluid collections in the MNHN), as

180 well as three jar sealants selected for their ubiquity in fluid collections (fig. 1) have

181 been analyzed by FT-IR spectroscopy and Py-GC/MS to evaluate the potentialities of

182 this experimental approach for the characterization of unknown samples of jar

183 sealants before a more systematic screening of the fluid collections in the museum is

184 initiated.

$<<$ Insert figure 1 here $>>$

Py-GC/MS analyses were performed using a vertical micro-furnace type pyrolyser

PY-2020iD (Frontier Lab, Japan) directly connected to the injection port of a

Shimadzu QP2010 gas chromatograph linked with a Shimadzu QP2010Plus

quadrupole mass spectrometer (Shimadzu, Champs-sur- Marne, France). The sample was firstly diluted in chloroform $\left(\mathrm{CHCl}_{3}\right)$ to obtain low concentrations of materials in the low $\mu \mathrm{g}$ range when analyzed by pyrolysis (typically, the concentration was calculated to allow the deposition of ca. $1.5 \mu \mathrm{g}$ of sample in the stainless-steel 
sample cup). A derivatization reactant, tetramethyl ammonium hydroxide, was added to the previous sample solution to methylate the hydroxyl functional groups (of acids and alcohols) expected to be present within the jar sealant samples. Such in-situ derivatization is currently conducted during Py-GC/MS experiments to allow a better separation of polar compounds during the chromatographic separation (Challinor 2001). The sample cup was placed on top of the pyrolyser at near ambient temperature. For the analysis, the sample cup was introduced into the furnace at 600 ${ }^{\circ} \mathrm{C}$, and then the temperature program of the gas chromatograph oven was started. The Py-GC interface was held at $320^{\circ} \mathrm{C}$. Chromatographic separation was carried out on an Agilent DB5-ms 5\% phenyl-95\% dimethyl polysiloxane fused silica capillary column (30 m long, $0.25 \mathrm{~mm}$ inner diameter, and coated with a $0.25 \mu \mathrm{m}$ film thickness). The oven temperature was initially held at $40^{\circ} \mathrm{C}$ for $8 \mathrm{~min}$, and then ramped at $10^{\circ} \mathrm{C} \mathrm{min}-1$ to $340^{\circ} \mathrm{C}$, where it was held for $10 \mathrm{~min}$. The total duration of GC analysis was 48 min. The helium carrier gas Alphagaz 1 (Air Liquide, France) was used in the linear velocity mode $\left(1 \mathrm{~mL} \mathrm{~min}^{-1}\right)$. The injector was held at $280^{\circ} \mathrm{C}$ and used in split mode (1:10 of the total flow). The mass spectrometer was operated at 10,000 mass unit per second $\left(\mathrm{u} \mathrm{s}^{-1}\right)$, with a scan range from 40 to $800 \mathrm{u}$, using electron ionization (EI) at $70 \mathrm{eV}$. The interface was kept at $300^{\circ} \mathrm{C}$ and the MS source at $200{ }^{\circ} \mathrm{C}$. Identifications were achieved on the basis of El mass spectra by interpretation of the main fragmentations and using the NIST MS library (NIST/NIH/EPA Mass Spectral Library 2011).

The Fourier transform infrared (FT-IR) data were acquired in the ATR mode using a Thermo Nicolet 6700 (Thermo Scientific, Courtaboeuf, France) within the range 500$4000 \mathrm{~cm}^{-1}$. Each FT-IR spectrum was the result of four co-added scans at a nominal resolution of $4.0 \mathrm{~cm}^{-1}$. 
FT-IR analysis

As a first approach, screening of the samples was conducted by FT-IR spectroscopy.

Figure 2 shows the FT-IR absorbance spectra of the chosen reference samples: (2a) commercial beeswax, $(2 b)$ paraffin, and $(2 c)$ resin of the MNHN collections.

Characteristic IR band vibrations of chemical functions present in these samples can be observed (Derrick et al. 1999).

As generally noticed in FT-IR spectra, band assignment in the $4000-1500 \mathrm{~cm}^{-1}$ region is quite straightforward. Wax samples are characterized by the stretching of their numerous methylene groups at $2920 \mathrm{~cm}^{-1}$ and $2850 \mathrm{~cm}^{-1}$, confirmed by the sharp doublets at $1470-1460 \mathrm{~cm}^{-1}$ and $729-719 \mathrm{~cm}^{-1}$ (fig. 2a, commercial beeswax). Bending of these methylene groups appeared around $1470 \mathrm{~cm}^{-1}$. In beeswax, longchain hydrocarbons with $\mathrm{CH}_{2}$ methylene groups and $\mathrm{CH}_{3}$ terminal groups finally show similarity to the spectra of paraffins (fig. 2b, paraffin). Specifically, aliphatic ester groups of beeswax account for the stretching bands observed at $1710 \mathrm{~cm}^{-1}$ and 1170 $\mathrm{cm}^{-1}$ for $\mathrm{C}=\mathrm{O}$ and $\mathrm{C}-\mathrm{O}$ bonds, respectively.

For the reference resin sample (fig. $2 \mathrm{c}$ ), a broad band assigned to $\mathrm{O}-\mathrm{H}$ stretch was observed around $3000-3500 \mathrm{~cm}^{-1}$. The expected cyclic ring structures gave strong C$\mathrm{H}$ stretching vibrations found at 2930 and $2870 \mathrm{~cm}^{-1}$. Due to a variety of molecular environments for the methylene groups within the resin, and because there are several methyl $\left(\mathrm{CH}_{3}\right)$ end groups, these $\mathrm{C}-\mathrm{H}$ stretches are not as sharp and as well 
separated as those seen in the beeswax and paraffin samples. A strong carbonyl band centered at $1690 \mathrm{~cm}^{-1}$ was observed for which enlarged band shape can be attributed to resin degradation and oxidation. Bands observed in the region 500-1500 $\mathrm{cm}^{-1}$, where bands at $1460 \mathrm{~cm}^{-1}, 1380 \mathrm{~cm}^{-1}$ are assigned to $\mathrm{CH}$ group bending, and other bands in the $1300-900 \mathrm{~cm}^{-1}$ region could be assigned to C-O stretching bands in accordance with the expected rosin origin of the sample.

$<<$ Insert figure 2 here >>

Comparatively, considering the above assignments, if FT-IR spectra of the three selected jar sealants (fig. 3) showed some similarities to the reference samples, presence of additional bands revealed the possible presence of other components for two of them. Indeed, among these sealants, the jar sealant A8407 (fig. 3a) presented characterictic bands $\left(2920 \mathrm{~cm}^{-1}\right.$ and $\left.2850 \mathrm{~cm}^{-1}, 1460 \mathrm{~cm}^{-1}, 719 \mathrm{~cm}^{-1}\right)$ of the methylene groups of beeswax as well as the stretching bands for $\mathrm{C}=\mathrm{O}$ and $\mathrm{C}-\mathrm{O}$ bonds at $1740 \mathrm{~cm}^{-1}$ and $1170 \mathrm{~cm}^{-1}$, respectively. From these assignments, sample A8407 could be attributed to a beeswax-based composition. Only one additional band at $1380 \mathrm{~cm}^{-1}$ was observed that could not be definitely assigned to a reference. Sample 1974-66 (fig. 3b) showed mainly similarities with the previous A8407 sealant and beeswax, but showed discrepancies in the region $1240-820 \mathrm{~cm}^{-1}$, and a more intense doublet at $717-719 \mathrm{~cm}^{-1}$. The last sample, 1924-185, showed patterns in common with previous sealants but showed noticeable differences in the region $1260-500 \mathrm{~cm}^{-1}$, which indicates the presence of other components than those observed in beeswax. 
<<Insert figure 3 here >>

As stated above, Py-GC/MS analysis is based on pattern recognition of components issued from thermal degradation of a given polymer, which results in a fingerprint identification of this sample. Consequently, the reference samples investigated here (fig. 1) were pyrolyzed under the experimental conditions described above to collect characteristic fingerprints of materials likely present in historic recipes for jar sealants in the MNHN collections. Figure 4 reports the chromatographic fingerprint of the reference commercial beeswax in which a typical distribution pattern of the main components of beeswax can be observed. These components are mainly long-chain odd alkanes showing a peak distribution spanning from C23 (tricosane) to C35 (pentatriacontane) centered around the C27 congener (heptacosane), and methylated long-chain acids showing a peak distribution with a maximum at C24:0 (tetracosanoic acid methyl ester). Additionnally, hexadecanoic acid methyl ester, octadecenoic acid methyl ester, and octadecanoic acid methyl ester were detected as first eluting compounds. These latter components were attributed to native sideproducts in beeswax or products generated by the thermal decomposition of longchain palmitate esters present in beeswax but not eluted under the present chromatographic conditions (Tulloch 1972). Details for the assignment of the observed main products from beeswax pyrolysis are reported in Table 1. 
287 Comparatively, the reference paraffin presented a simpler fingerprint (fig. 5) with the main distribution of long-chain alkanes of an even number of carbons centered arround the C24 (tetracosane). Details for the assignment of the observed main products from beeswax pyrolysis are reported in table 2. Py-GC/MS of the reference resin sample (not shown here) presented peaks assigned to hexadecanoic acid methyl ester and octadecanoic acid methyl ester with numerous additional peaks, corresponding to terpenic compounds, which led to assigning this resin sample to a pine resin, likely rosin.

$<<$ Insert figure 5 here $>>$

$<<$ Insert table 2 here $>>$

Results from the Py-GC/MS analysis of the three investigated jar sealant samples: A8407, 1924-185 and-1974-66 are visualized in figure 6. Sample A8407 (fig. 6a) presents a distribution of peaks very similar to the reference beeswax sample (fig. 4), in particular with a distribution of long-chain alkanes of odd-numbered carbon atoms these observations, and at the present state of the investigation, sample A8407 can be attributed to beeswax as a principal ingredient in its composition. In comparion, sample 1974-66 (fig. 6c) shows a very divergent distribution of peaks in its characteristic fingerprint with predominant long-chain alkanes of an even number of 
carbons which led to assigning paraffin as a main component of this jar sealant. However, peaks corresponding to terpenic compounds are also detected in the chromatogram demonstrating the presence of at least one other component in this sample, likely a pine resin which showed similarities with the reference resin sample from the MNHN collections. The sample 1924-185 (fig. 6b) is characterized by a lower response under our pyrolysis conditions resulting in a lower signal-to-noise ratio for the peaks detected in the chromatogram. No satisfactory explanation can be drawn at this time from this observation: a mineral charge in the jar sealant sample, as suggested by the presence of numerous bands in the region $500-1400 \mathrm{~cm}^{-1}$ in the FT-IR spectrum (fig. 3c), can perturbate the pyrolysis process; on the other hand, a lower solubility of the sample could be proposed as a hypothesis. However, sample 1924-185 showed a distribution of peaks corresponding mainly to a series of longchain alkanes centered around the C26 (hexacosane) congener attributing the composition of this jar sealant to a paraffin-like composition, even if minor methyl esters were also detected as additives.

$<<$ Insert figure 6 here $>>$

Principal component analysis analysis

In order to improve the chosen approach based on a rapid screening by Py-GC/MS analysis, semi-quantitative experiments were conducted with the reference sample and the jar sealant samples. Quantification in Py-GC/MS experiments is difficult and neccesitates careful analysis of experimental results, in particular because the pyrolysis process introduces possible sources of variability during the experiments. In 
order to reduce the effects of the numerous factors that potentially influence the analytical results, heneicosanoic acid methyl ester $\left(\mathrm{C}_{22} \mathrm{H}_{44} \mathrm{O}_{2}\right)$ was added as an internal standard to each sample prior to analysis for the statistical treatment of data using a multivariate analysis (principal component analysis PCA). As the ionization response of acid methyl esters can be different from those of alkanes, a response factor for the integration of peak areas was applied for data treatment; this factor was calculated by comparing the peak area of the integrated peaks of the standard methyl ester (C22) to the tetracosane (C24) in an equimolar solution of both analyzed by GC/MS.

As a result, the PCA analysis of experimental data considering only the esters and alkanes present in the chromatograms provides a net distinction of the different samples (beeswax and the three jar sealant samples on the score plot are shown in fig. 7a). Contribution of samples to their PC1 and PC2 loading in principle component analysis are characteristic and dependent on their composition, and result in noticeable variations in peak areas of their main components.. Sample 1974-66, however, varies in its distribution among the three replicates. At the present state of the investigations, this was attributed with difficulties of correctly solubilizing paraffin samples homogeneously, which may amplify the variance in the principle component analysis.

The loading plot (fig. 7b) allowed the differentiation of nine main components for the discrimination of samples based on the analysis of their proportion of long-chain alkanes and long-chain methyl esters under Py-GC/MS analysis, identifying beeswax as a possible component of jar sealants. Besides characteristic methyl esters detected in beeswax, six long-chain alkanes of odd and even carbon numbers were 
revealed as potential discriminants for the characterization of sample composition. This result is promissing for a future screening of jar sealant samples on a larger scale.

$<<$ Insert figure 7 here >>

\section{Conclusions}

This approach, which is based on the development of an analytical protocol using FT-IR spectroscopy and Py-GC/MS, allows characterization of sealant components commonly encountered in historic fluid collections. FT-IR spectroscopy is an efficient way to detect the main components of unknown jar sealants, which allows the classification of such unknown sealants into different groups according to their most likely composition. Py-GC/MS, using polymer fingerprints, allows a more precise identification of components of the jar sealant recipes. Both techniques are opened to multivariate data analysis that can amplify and enhance the results. In particular, the use of Py-GC/MS can be a very efficient way to simplify the analysis of experimental results as illustrated by the extraction of nine potential markers for the discrimination of jar sealant containing beeswax and paraffin samples.

Our knowledge of sealant composition in fluid collections as well as correlation of this information to their manufacture and date of preparation is essential for a conservation approach, and for the perpetuation of natural history fluid collections. 
378 However, this knowledge is often limited because of various constraints inherited

379 from historical collections. Our new experimental approach to detect and identify the 380 composition of jar sealants is a promising tool to unlock past knowledge to better 381 understand the history and conservation of our fluid collections. Its application has

382 potential for other collections and hopefully will be applied more widely, and could be 383 promissingly enlarged to other collections.

386 The authors would like to thank the reviewers for their thoughtful comments and 387 efforts towards improving the manuscript. 


\section{Résumé}

Au fil des siècles, la composition des lutages dans les collections en fluides des musées d'histoire naturelle a changé, malheureusement ces changements sont peu documentés. Par conséquent, il est primordial d'accroître nos connaissances sur l'évolution au cours des différentes époques de la composition des lutages des collections en fluide.

L'approche proposée repose sur le développement d'un protocole analytique basé sur l'utilisation de la spectroscopie FTIR et de la pyrolyse-GC / MS pour caractériser la composition des lutages rencontrés dans les collections en fluides du MNHN.

Cette approche s'est avérée efficace pour l'identification et la caractérisation de cires et de résines dans les échantillons de lutages étudiés. Ces premiers résultats sont très prometteurs et ces analyses doivent être poursuivis à plus grande échelle afin d'obtenir une analyse exhaustive des collections en fluides du MNHN.

\section{References}

Burroughs, G.E., K. Makos, C. Hawks, and T.J. Ryan. 2006. Exposure of museum staff to formaldehyde during some wet specimen activities. Collection Forum 20(12):49-54.

Carter, J., and D. Neumann. 2016. Basic techniques in Collection Care - Wet Collection II". $31^{\text {th }}$ Annual SPNHC Meeting, Workshop "Basic collection techniques Wet collections”, 25 June 2016, Museum für Naturkunde, Berlin.

Challinor, J.M. 2001. Review: the development and applications of thermally assisted hydrolysis and methylation reactions. J. Anal. Appl. Pyr. 61: 3-34. 
414 Collins, C. 2014. Standards in the Care of Wet Collections. Notes from the Cloth 415 Makers Foundation Expert Workshop on Benchmark Standards for the Preservation on Wet Collections, http://conservation.myspecies.info/node/33

Daubenton, L-J-M. 1749. L'Histoire Naturelle générale et particulière : avec la Description du Cabinet du Roy, III, Paris, Imprimerie Royale, 176-195.

Daubenton, L-J-M. 1784. Sur les moyens de conserver les quadrupèdes ovipares, et d'autres animaux, après la mort, Encyclopédie méthodique ou par ordre de matières. Histoire naturelle des oiseaux, Paris, Plomteux, II, 564-570.

Defendini, L. 2016. L'impact des collections patrimoniales sur la santé. La lettre de I'OCIM 168: 12-15.

Derrick, M.R., D. Stulik, D., and J.M. Landry, J.M. 1999. Infrared Spectroscopy in 425 Conservation Science, The Getty Conservation Institute, Los Angeles, USA. 252 pp. Herbin, M. 2013. La conservation des collections en fluide. CeROArt [Online], Online since 18 August 2013, URL: http://journals.openedition.org/ceroart/3432; DOI: $10.4000 /$ ceroart.3432

Herbin, M. 2017. Quel devenir pour les collections anatomiques en fluide? Une approche historique. La Lettre de l'OCIM [On line], 170, online since 1 March 2018, URL : http://journals.openedition.org/ocim/1749; DOI: 10.4000/ocim.1749

Maissiat, J. 1847. Sur un moyen de fermer exactement les vases destinés aux collections d'histoire naturelle. Comptes rendus hebdomadaires des séances de I'Académie des sciences, XXIV (10) : 353-355. 
Moore, S. 2007. Old jar sealants. NatSCA News 12: 20-22.

437 NIST/NIH/EPA Mass Spectral Library 2011, Standard Reference Database 1, NIST 11.

438 Standard Reference Data Program, National Institute of Standards and Technology:

439 Gaithersburg, MD, USA.

440 Pequignot, A. 2019. Le lutage des collections en fluide: histoire d'une technique entre 441 pratique de cabinet et expériences de terrain. e-Phaïstos, VII-1 [On line], online since 44206 April 2019, URL : http://journals.openedition.org/ephaistos/4563; DOI:

$443 \quad 10.4000 /$ ephaistos.4563

444 Péron, F., and C-A. Lesueur. 1810. Mémoire sur la conservation des diverses

445 espèces d'animaux dans l'alcool. Journal de Physique, 81: 265-288.

446 Simmons, J.E. 2014. Fluid Preservation: A Comprehensive Reference. Rowman \& 447 Littlefield, Lanham. 347 pp.

448 Sobeih, K.L., M. Baron, and J. Gonzalez-Rodriguez, J. 2008. Recent trends and 449 developments in pyrolysis-gas chromatography. J. Chrom. A, 1186:51-66.

450 Tulloch, A.P. 1972. Analysis of whole beeswax by gas liquid chromatography. J. Am. 451 Oil Chem. Soc., 49: 609-610.

452 van Dam, A.J. 2000. The interactions of preservative fluid, specimen container and 453 sealant in a fluid collection. Collection Forum 14(1-2): 78-92. 
455 Table 1. Main products observed from the pyrolysis of reference beeswax with 456 corresponding retention times, molecular weights, formulas, and assignments.

\begin{tabular}{l|l|l|l}
$\begin{array}{l}\text { Retention } \\
\text { time } \\
(\text { min })\end{array}$ & $\begin{array}{l}\text { Molecular } \\
\text { mass } \\
(\mathrm{g} / \mathrm{mol})\end{array}$ & $\mathrm{Formula}$ & Assignment \\
\hline 26.71 & 270 & $\mathrm{C}_{17} \mathrm{H}_{34} \mathrm{O}_{2}$ & Hexadecanoic acid methyl ester \\
28.41 & 296 & $\mathrm{C}_{19} \mathrm{H}_{36} \mathrm{O}_{2}$ & Octadecenoic acid methyl ester \\
28.65 & 298 & $\mathrm{C}_{19} \mathrm{H}_{38} \mathrm{O}_{2}$ & Octadecanoic acid methyl ester \\
30.14 & 324 & $\mathrm{C}_{23} \mathrm{H}_{48}$ & Tricosane \\
30.98 & 338 & $\mathrm{C}_{24} \mathrm{H}_{50}$ & Tetracosane \\
31.78 & 352 & $\mathrm{C}_{25} \mathrm{H}_{52}$ & Pentacosane \\
32.06 & 354 & $\mathrm{C}_{23} \mathrm{H}_{46} \mathrm{O}_{2}$ & Docosanoic acid methyl ester \\
32.55 & 366 & $\mathrm{C}_{26} \mathrm{H}_{54}$ & Hexacosane \\
33.29 & 380 & $\mathrm{C}_{27} \mathrm{H}_{56}$ & Heptacosane \\
33.55 & 382 & $\mathrm{C}_{25} \mathrm{H}_{50} \mathrm{O}_{2}$ & Tetracosanoic acid methyl ester \\
34.01 & 394 & $\mathrm{C}_{28} \mathrm{H}_{58}$ & Octacosane \\
34.72 & 408 & $\mathrm{C}_{29} \mathrm{H}_{60}$ & Nonacosane \\
34.97 & 410 & $\mathrm{C}_{27} \mathrm{H}_{54} \mathrm{O}_{2}$ & Hexacosanoic acid methyl ester \\
35.38 & 422 & $\mathrm{C}_{30} \mathrm{H}_{62}$ & Triacontane \\
36.04 & 436 & $\mathrm{C}_{31} \mathrm{H}_{64}$ & Hentriacontane \\
36.30 & 438 & $\mathrm{C}_{29} \mathrm{H}_{58} \mathrm{O}_{2}$ & Octacosanoic acid methyl ester \\
36.67 & 450 & $\mathrm{C}_{32} \mathrm{H}_{66}$ & Dotriacontane \\
37.17 & 464 & $\mathrm{C}_{33} \mathrm{H}_{68}$ & Tritriacontane \\
37.55 & 466 & $\mathrm{C}_{31} \mathrm{H}_{62} \mathrm{O}_{2}$ & Triacontanoic acid methyl ester \\
38.66 & 492 & $\mathrm{C}_{35} \mathrm{H}_{72}$ & Pentatriacontane \\
38.76 & 494 & $\mathrm{C}_{33} \mathrm{H}_{66} \mathrm{O}_{2}$ & Dotriacontanoic acid methyl ester \\
40.11 & 522 & $\mathrm{C}_{35} \mathrm{H}_{70} \mathrm{O}_{2}$ & Tetratriacontanoic acid methyl ester \\
\hline & &
\end{tabular}


459 Table 2. Main products observed from the pyrolysis of reference paraffin with

460 corresponding retention times, molecular weights, formula and assignments.

461

\begin{tabular}{l|l|l|l}
\hline $\begin{array}{l}\text { Retention } \\
\text { time } \\
(\mathrm{min})\end{array}$ & $\begin{array}{l}\text { Molecular } \\
\text { mass } \\
(\mathrm{g} / \mathrm{mol})\end{array}$ & Formula & Assignment \\
\hline 26.817 & 270 & $\mathrm{C}_{17} \mathrm{H}_{34} \mathrm{O}_{2}$ & Hexadecanoic methyl ester \\
28.369 & 296 & $\mathrm{C}_{21} \mathrm{H}_{44}$ & Heicosane \\
28.660 & 298 & $\mathrm{C}_{19} \mathrm{H}_{38} \mathrm{O}_{2}$ & Octadecanoic acid methyl ester \\
29.253 & 310 & $\mathrm{C}_{22} \mathrm{H}_{46}$ & Docosane \\
30.120 & 324 & $\mathrm{C}_{23} \mathrm{H}_{48}$ & Tricosane \\
30.959 & 338 & $\mathrm{C}_{24} \mathrm{H}_{50}$ & Tetracosane \\
31.769 & 352 & $\mathrm{C}_{25} \mathrm{H}_{52}$ & Pentacosane \\
32.554 & 366 & $\mathrm{C}_{26} \mathrm{H}_{54}$ & Hexacosane \\
33.317 & 380 & $\mathrm{C}_{27} \mathrm{H}_{56}$ & Heptacosane \\
34.057 & 394 & $\mathrm{C}_{28} \mathrm{H}_{58}$ & Octacosane \\
34.773 & 408 & $\mathrm{C}_{29} \mathrm{H}_{60}$ & Nonacosane \\
35.474 & 422 & $\mathrm{C}_{30} \mathrm{H}_{62}$ & Triacontane \\
36.153 & 436 & $\mathrm{C}_{31} \mathrm{H}_{64}$ & Hentriacontane \\
36.807 & 450 & $\mathrm{C}_{32} \mathrm{H}_{66}$ & Dotriacontane \\
\hline
\end{tabular}

462

463

464

465 
467

468

469

470

471

472

473

474

475

476

477

478

479

480

481

482

483

484

485

Figure 1. (a) Commercial beeswax, (b) reference paraffin from the MNHN collections, (c) reference resin from the MNHN collections, (d) sample A8407 - a waxy red-violet sealant covered with a metal sheet dating from 1893, (e) sample 1924-185 - a waxy brown sealant dating from 1924, (f) sample 1974-66 - a waxy yellowish sealant dating from 1924.

Figure 2. FT-IR spectra of reference samples of commercial beeswax (blue), paraffin (orange), resin (green) from the MNHN collections.

Figure 3. FT-IR spectra of jar sealant samples: A8407 (blue), 1974-66 (red), 1924185 (green).

Figure 4. Chromatogram obtained from the Py-GC/MS analysis of reference beeswax at $600^{\circ} \mathrm{C}$ with characteristic distributions of long-chain esters (orange squares) and odd alkanes (orange plain circles).

Figure 5. Chromatogram obtained from the Py-GC/MS analysis of reference parafin at $600^{\circ} \mathrm{C}$ with a characteristic distribution of long-chain alkanes (orange plain circles).

Figure 6. comparison of the chromatograms obtained from the Py-GC/MS analysis of the investigated jar sealant samples: (a) sample A8407 (b) sample 1924-185 (c) sample 1974-66. The following components are reported in the figure as follow: longchain esters (orange squares), long-chain alkanes (orange plain circles), terpenic compounds (green plain circles). 
486 Figure 7: (a) Score plot and (b) loading plot from the comparison of reference

487 samples and unknown jar sealants considering only compounds originating from wax 488 (esters and alkanes).

489 Figure 1

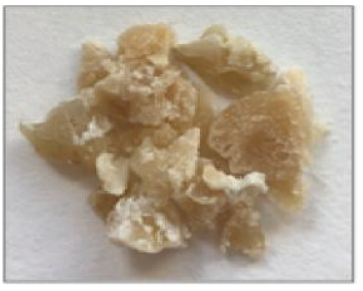

(a)

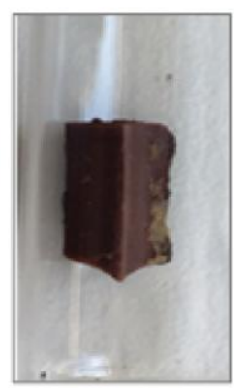

(d)

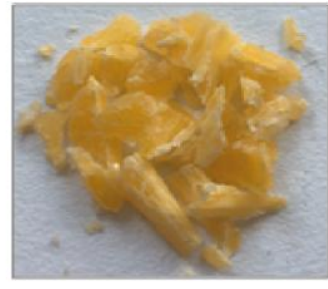

(b)

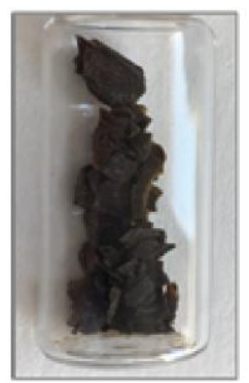

(e)

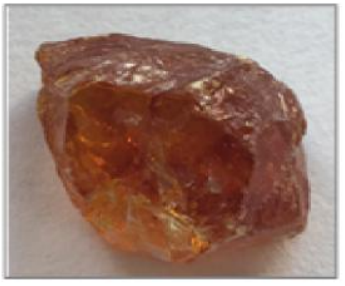

(c)

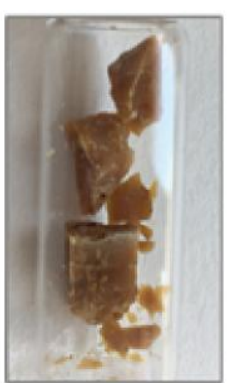

(f)

$491 \quad$ Figure 2 


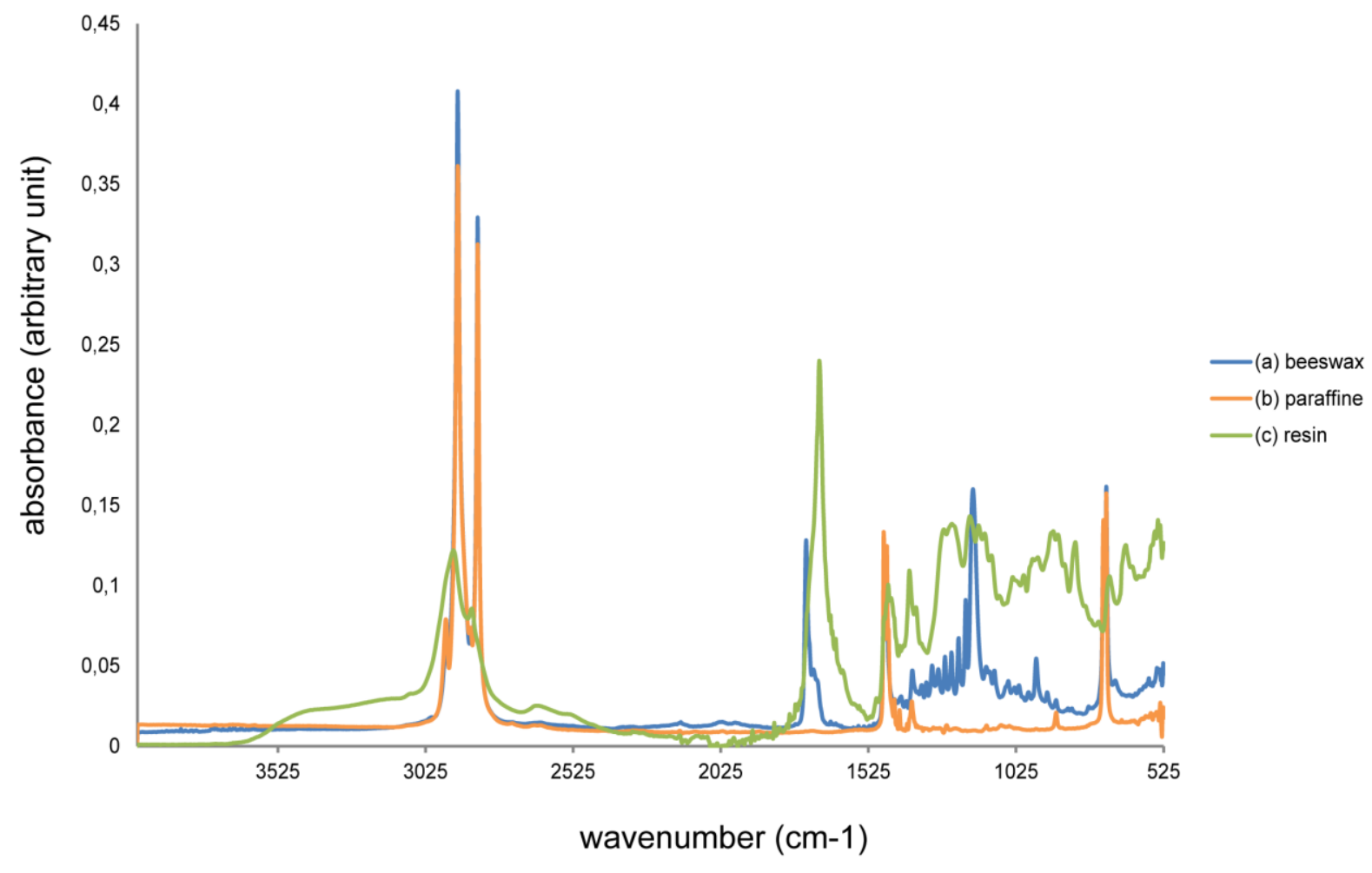

493

$494 \quad$ Figure 3

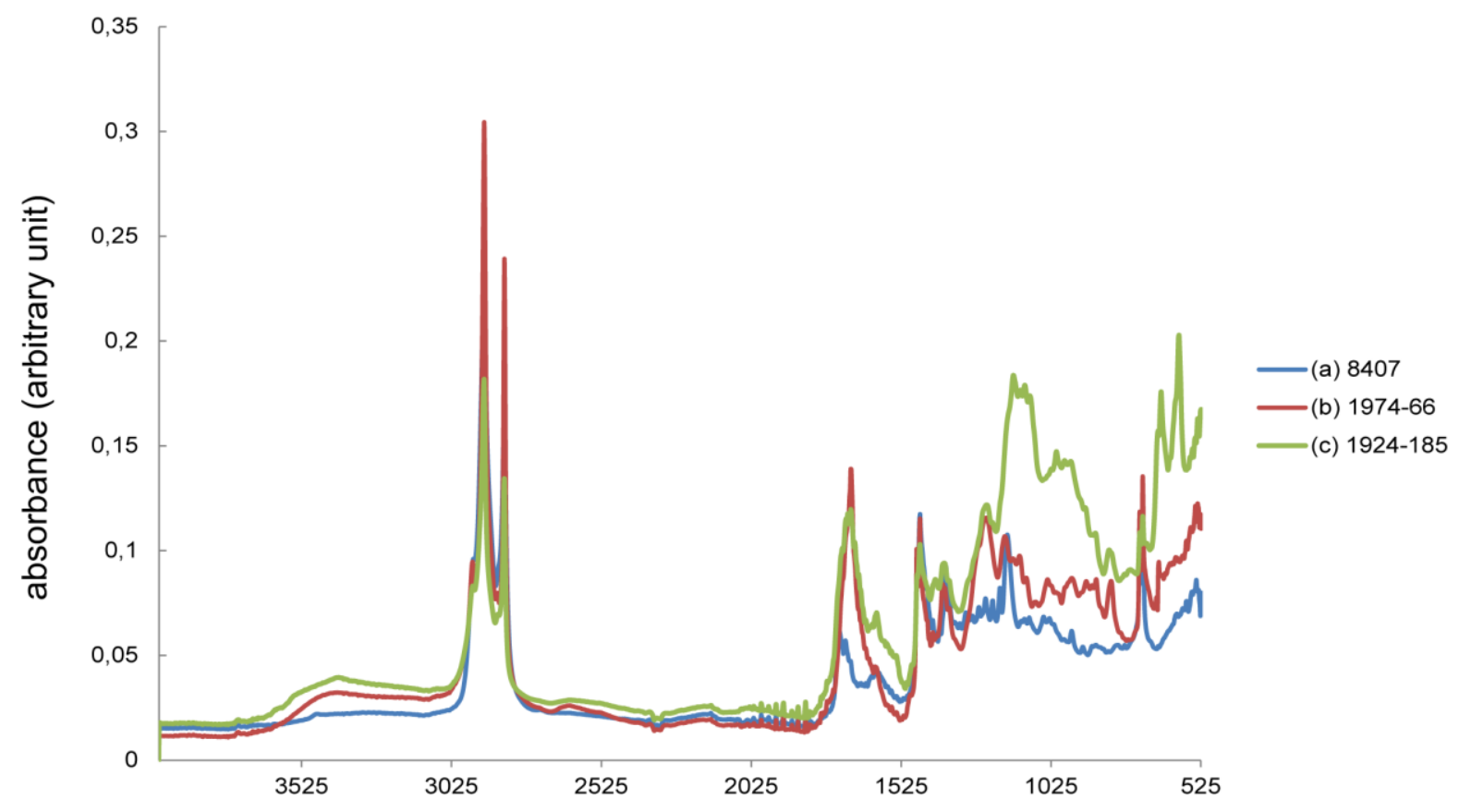

wavenumber $(\mathrm{cm}-1)$

497 Figure 4 


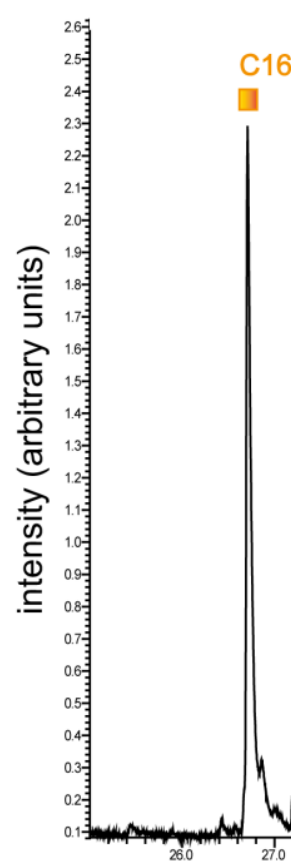

498

499

500

Figure 5

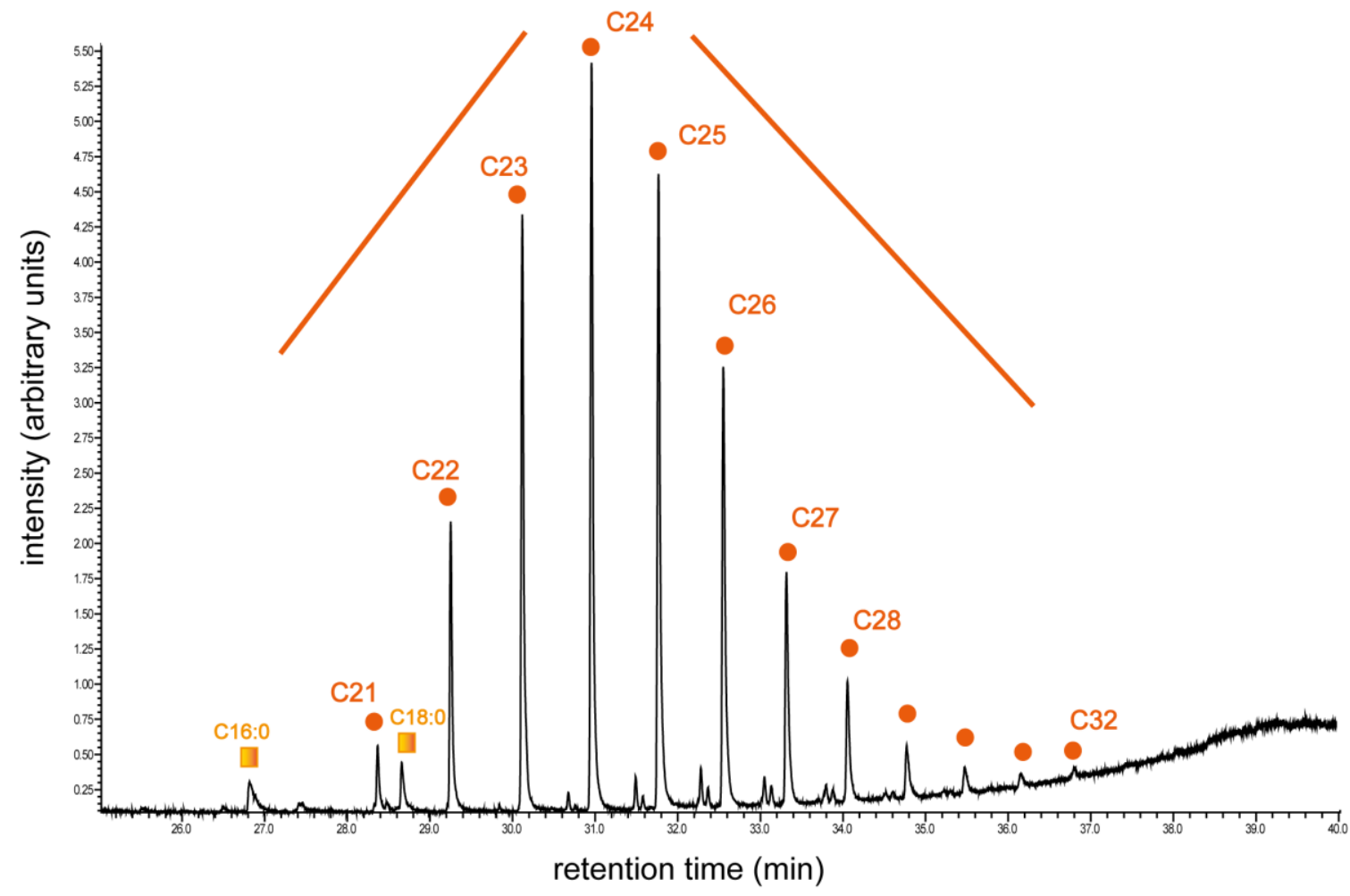

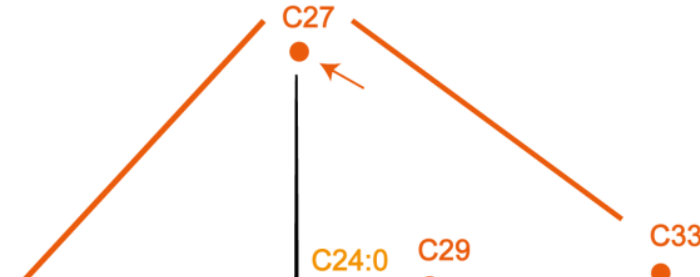

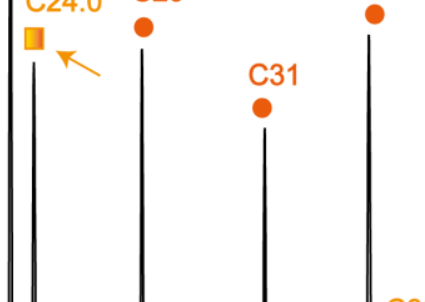

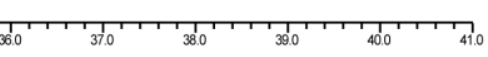




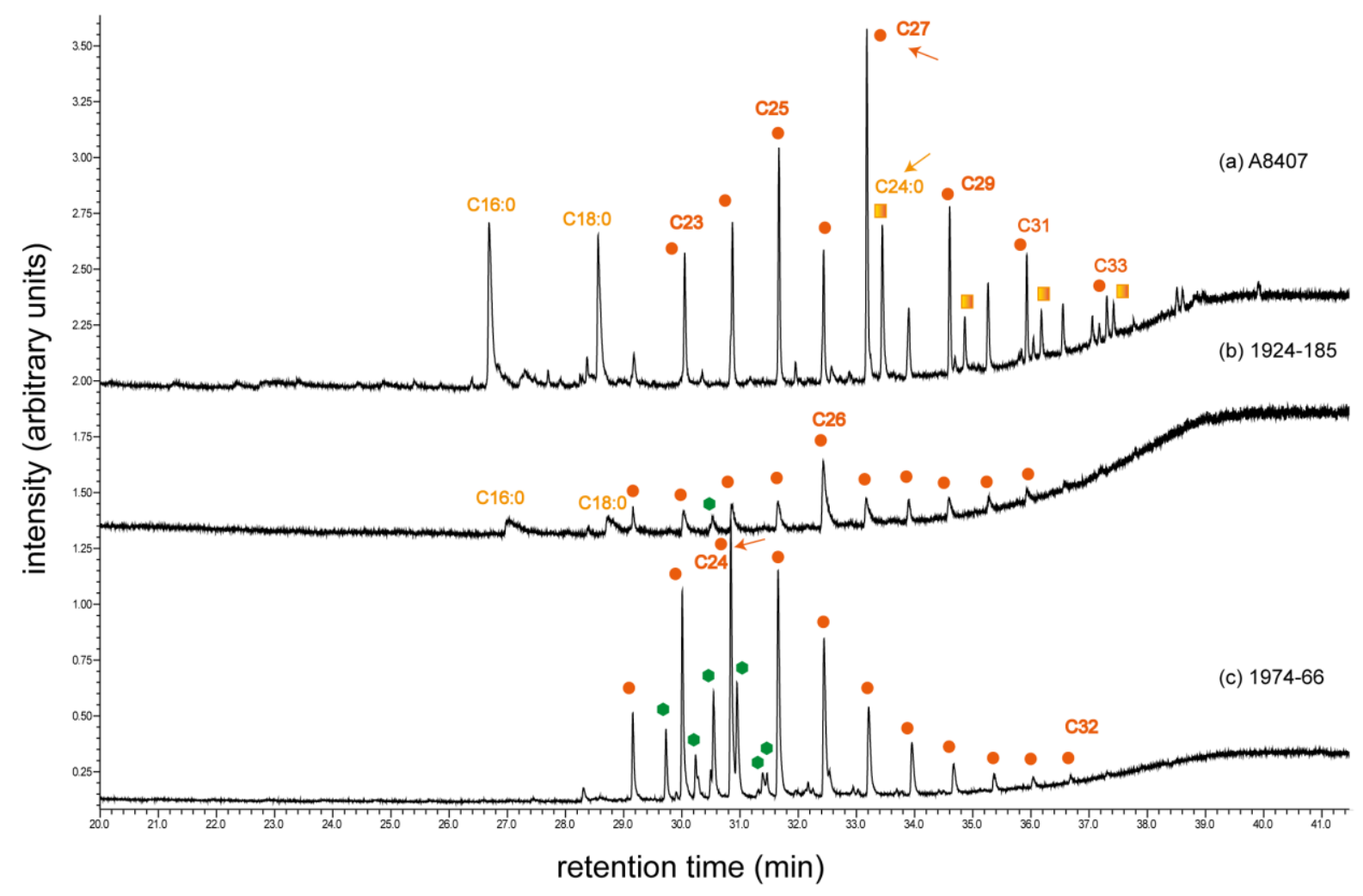

504

$505 \quad$ Figure 7

(a)

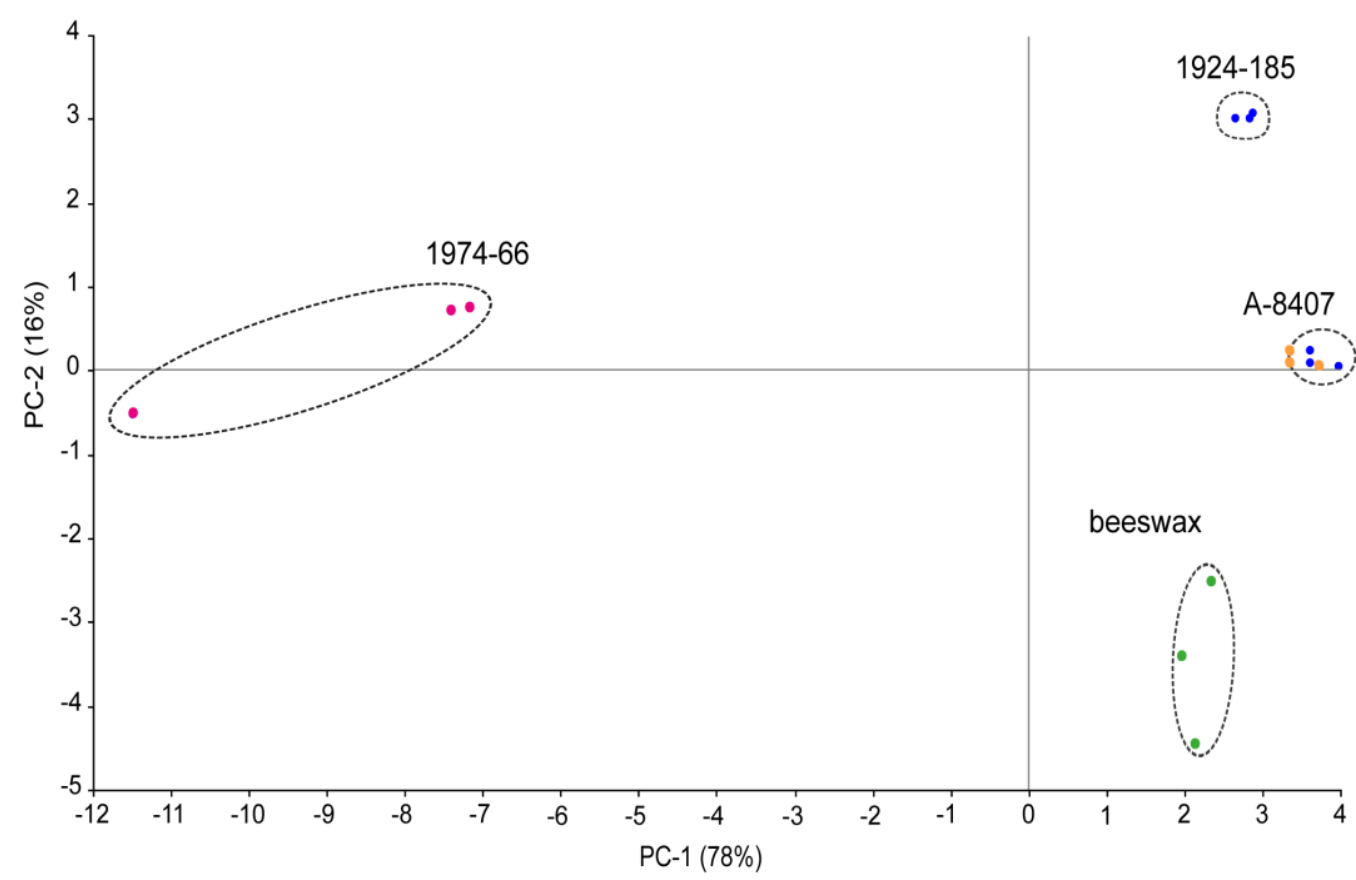


(b)

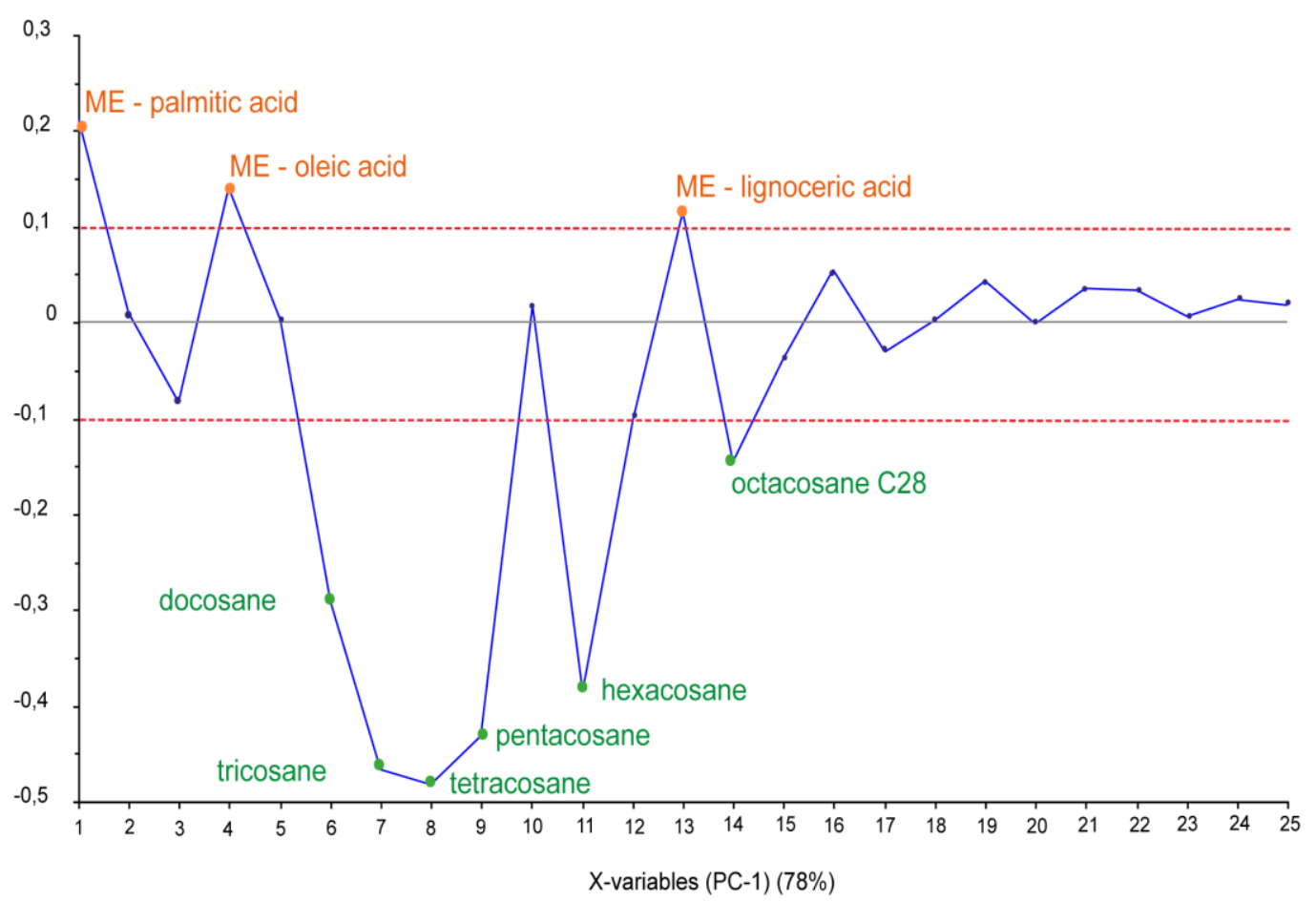

507

508 